Session 2793

\title{
A Pilot Study for Creativity Experiences in a Freshman Introduction to Engineering Course
}

\author{
Cynthia Mann, Karen A. High \\ Oklahoma State University
}

\begin{abstract}
A program launched at Oklahoma State University seeks to enhance the creative abilities of engineering students. The project objectives are to: improve recruitment and retention; increase the value of our graduates, and maximize job and lifetime satisfaction for our engineers.

The motivation for this program comes from the observation that engineering students may not be enjoying their education to its fullest extent. Students turn away from engineering because they feel it is too abstract and not practical. They feel as though it requires a lot of hard work for little benefit. Students do not think engineering will be fun. The truth is that engineering draws on all of one's abilities and experiences. Engineering requires more than the math and logical thinking skills that we spend our class time learning. Good engineering requires creativity.

One might say that even though creativity is important, it is not a skill that can be 'taught' and therefore requires no further concern. We disagree. Whether or not we can 'teach' engineering students to be creative, we can provide an environment that supports creative thinking. We can allow students to find their own creative and unique solutions to engineering problems. While we understand that there is not room for creativity in every problem (you cannot change the laws of nature), we believe there is room for creativity throughout an engineering curriculum.

Our initial focus has been on a one-credit freshman orientation course. The major course objective is to introduce the students to engineering. The majority of the creativity experiences have focused on a Pizza Project. The Pizza Project was designed as a tool to teach students to use their creative abilities and help them understand what an engineer really does. More importantly, it was designed to impart to them that engineering is useful and fun.
\end{abstract}

\section{Introduction}

College students do not see engineering as a creative field of study. Students see engineering as math, as an abstraction, as disconnected from reality. Freshmen often look at the daunting curriculum and see an abundance of work with little or no reward. What is not apparent in the underclass-engineering curriculum is the amount of creativity that is necessary to solve industrial problems ${ }^{1}$. This becomes more apparent in advanced courses, such as senior design, but we must be able to retain students until that level. 
Students retained until graduation sometimes also express apathy toward the field of engineering. Upon finally reaching graduation, some are so burned-out that they are not able to look forward to beginning a new career. At OSU some were specifically asking for more opportunity to have creative input in their education. It was believed that if they could take more ownership in their projects - by expressing their unique ideas, that they would feel more pride in their work ${ }^{2}$. Thus projects that had been exhausting because of their abstractness might become less exhausting because of the personal pride and motivation of working toward one's own creative expression ${ }^{3}$.

Additionally, industrial employers seek innovative solutions to their problems and new engineers should be practiced in creative exploration of problems at hand. It is unrealistic to expect a student who has never solved a problem that did not come packaged with all the necessary information to adjust easily to the "real world" where information is almost never readily available in its most useful form. This brought about the birth of this research into adding more creativity to engineering education. Knowing the goals and benefits of increased creativity, the questions of how, when and where to implement it still remained.

Looking at upperclass courses, they are full of complex technical ideas. However, lab courses and projects do offer the opportunity to use creativity. Why then do students feel stifled? In most cases students are afraid to go out on a creative limb - grades are a driving force for most student effort. Nobody wants to put his or her grade in jeopardy just to view an assignment from an alternate perspective. The stereotypical learning environment is highly structured, not supportive of unique ideas about how to do things. This is often because the more alike a group of students is, the easier it is to teach them. The "read and regurgitate" style of the first 12 to 14 years of education ingrains the idea that all that the professor wants students to know is what the professor has already said. However, this will not be an acceptable mode of thought in industry. Students must learn that independent thought and creative problem solving are valuable skills. This is accomplished by providing a learning environment that supports these traits.

Underclass courses then are preferable because the earlier that creative problem solving is taught, the more use a student may make of it. However, these classes offer different challenges.

Though the technical content of an under-class course may be lighter, one is also dealing with less mature individuals. It is also in these courses that the "basics" are being taught. Therefore, if students do not yet understand the basics, how can they possibly apply these concepts to creative problem solving?

The solution was to teach the complete problem solving process using non-technical problems. Non-technical problems are also preferable because expertise is a prerequisite for creativity ${ }^{4}$. It is unrealistic to expect someone to be creative in an unfamiliar situation. The pilot study implementing these exercises was in one section of the ENGR 1111, freshman orientation course, in the Fall 2002 semester.

In order to assess student perceptions, and hopefully the benefits of the course, a survey was written to assess student attitudes and confidence with several aspects of the course. The intention was to compare beginning of course responses to end of course responses, and make a formal proposal to implement additional creativity exercises in other underclass courses during the 
Spring 2003 semester.

\section{Background}

First semester freshmen and transfer students are required to take an orientation class at most universities. At OSU, this is a one credit hour course which has major objectives of introducing students to the different engineering disciplines as well as familiarizing them with the campus and college life (library/counseling/career services, computer labs, study skills etc.). In order to meet certain ABET criteria, the College of Engineering requires certain activities to be accomplished in all ENGR 1111 sections. A list of these requirements, as well as a few other common exercises done in the average ENGR 1111 course is shown in Table 1. Creative problem solving techniques and a design project were added to the curriculum of one section of this orientation course having 20 enrolled students.

Table 1. Required and Common Activites for ENGR 1111.

\begin{tabular}{|l|}
\hline \multicolumn{1}{|c|}{ ENGR 1111 Activities Required by the College } \\
\hline At least one team activity. (ABET outcome d) \\
\hline At least one activity involving ethics. (ABET outcome f) \\
\hline At least one oral presentation. (ABET outcome g) \\
\hline Library training and assignment. (ABET outcome l) \\
\hline Requirement to attend a professional society meeting or career fair. (ABET outcome l) \\
\hline At least one activity involving contemporary issues. (ABET outcome j) \\
\hline Show competency in MS Word, Excel, and PowerPoint. (ABET outcome k) \\
\hline Awareness of OSU Computer Services. (ABET outcome k) \\
\hline \multicolumn{1}{|c|}{ Additional activities common in ENGR 1111 } \\
\hline Academic Success / Study Skills / Time Management \\
\hline Personality typing using the Myer's Briggs Type Indicator \\
\hline Career Services Awareness / Resume Writing / Interviewing Strategies \\
\hline Planning of class schedules or a four-year Study Plan \\
\hline
\end{tabular}

Because of ease and availability, changes in the preliminary stages have been directed at the home department, Chemical Engineering. Before the Fall 2002 semester (in which the project occurred) the idea of adding creativity to specifically the ENGR 1111 course was proposed to the School of Chemical Engineering. Faculty were generally supportive, but needed more information before making drastic changes to their courses. Thus one of four sections taught by Chemical Engineering Faculty (the one taught by Dr. High) included the project and problem solving exercises. The section of interest was intended for prospective chemical engineering majors. Of the other three sections in the School, two were also for prospective chemical engineers, and one was for transfer students in all disciplines. During the Spring 2003 semester, the results of this pilot will be used to propose additional changes to all orientation sections in the college.

\section{Approach}

Because this was designed as a pilot study, it was important to collect information with which one could compare the performance and attitudes of students who completed the project with other students who did not. To this end a survey was constructed to gauge the students' confidence in 
the problem solving process as taught in the creativity enhanced section, as well as the other goals of the course. The survey was administered to the four sections of ENGR 1111 taught by Chemical Engineering faculty at the beginning and end of the Fall 2002 semester. Ultimately the information obtained throughout the pilot study will be used to propose a more in-depth assessment of effectiveness in increasing creativity and student retention.

The majority of the creativity exercises included in the study revolved around teaching a problem solving process through the use of the Pizza Project (described in detail below), however, the students also completed several other exercises. Recalling that there were already a significant number of objectives that must be completed in the course, many of the traditional activities were integrated into project related activities. A complete list of creative activities is given in Table 2 .

Table 2. New Creativity Exercises

\begin{tabular}{|l|}
\hline \multicolumn{1}{|c|}{ Creativity Exercises in the pilot study. } \\
\hline Product/Process Design: The candy airplane. \\
\hline Myers Briggs Type Indicator and Pizza Project Group Dynamics \\
\hline Problem Definition: What is the Pizza Problem? \\
\hline Brainstorming: How can we solve the Pizza Problem? \\
\hline Experimental Design: How will we know if our solution is good? \\
\hline In Class Experiments for the Pizza Problem \\
\hline Pizza Test and Presentations \\
\hline
\end{tabular}

The first group creative activity was to use a bag of assorted candy (gum, Tootsie Rolls, Lifesavers, etc.) and small office supplies (notepad, rubber bands etc.) to construct an airplane (based on appearance only). After creating a prototype, the groups were instructed to manufacture as many additional airplanes as they could in a specified time. During production time, the instructors simulated process upsets that the groups had to overcome (for example loss of raw materials, cutbacks in the workforce, employee injury etc.). The students employed great creativity, not only in the airplane designs, but also in working around the processing calamities. This activity led to a discussion of the manufacturing process and product design, and it was also a lot of fun! After this experience, the students understood that this was not going to be a "normal" class. They also began to realize that this was an atmosphere where positive feedback was readily available for unique responses.

The first day of class, each student was given a notebook to serve as a journal and a laboratory notebook for the project. Throughout the semester they were instructed to use the journal to complete some assignments, keep track of project related information (and data), and also provide feedback about class activities through journal entries. This was found to be an effective method of illustrating the importance of laboratory notebooks - a concept foreign to many engineering students. The success of this project relied on the students' comfort in interacting with the instructors, the notebooks seem to be a non-threatening forum for feedback.

The last 12 weeks of the semester integrated the Pizza Project into the class activities. They were placed in teams of four and given a scenario in which they were all design teams working for a company that had been contracted by Fred's Pizza. Unlike design problems that request a course of action given a well-defined problem, the students were instead given a symptom to alleviate: 
Customers of Fred's Pizza are calling in to complain that delivery pizzas are arriving cold, and that grease is leaking through the boxes and staining tablecloths.

This nebulous statement was developed to reflect the nature of industrial problems. Unlike textbook exercises, in industry, we are not given all of the constants, variables, and conditions in a package. Instead, most industrial problems are only realized when the symptoms become apparent, it is then the job of the engineer to determine what real problem is causing the symptoms: exactly the type of creative experience that is rare to undergraduate education.

Statement of symptoms in hand, and groups of four assigned, students were sent to incubate until the next week when they began a guided journey through the problem solving process. Strategies for Creative Problem Solving 5 was used extensively to craft the classes' exercises in each step of the process. As we called them, the steps were (1) Problem Definition, (2) Brainstorming Solutions, (3) Deciding a Course of Action, (4) Implementing the Solution (experimentally), and (5) Evaluating the Solution. Each step involved an in-class group activity and a group homework assignment; many also had an individual assignment unrelated to the Pizza Project.

One major challenge was implementing an entire project in a one credit hour course without overloading the students. It was desirable to give group time during class, and not require extensive group meetings outside of class. Therefore many class periods were spent half disseminating information through lecture and half in group work. This forced the generation of several handouts to explain complex strategies in problem definition, brainstorming, etc. Hopefully, the students will find those resources useful in the future.

Throughout the project, students were encouraged to "research" the causes and effects of the symptom by directing questions to the instructors. In order to make decisions about how to solve the problem (alleviate the symptom), they needed more information. Information was only available on request, subsequently, depending on the questions the students asked, each group had different information on which to base their recommendations for improvement. Of course, when similar questions were asked, the groups received the same response to keep the information congruous. This method of providing information can be time consuming, but like an industrial problem, it was important to reward effort with a better understanding of the situation at hand.

A conscious effort was made to not steer the groups in the same direction. Diverse solutions were encouraged, and ideas about changing the pizza recipe and delivery methods were a portion of the final recommendations made by the class. However, in an effort to allow the opportunity to see a solution at work, students were given one class period to perform experiments on their solution to the problem - as they had defined it. This resulted in each group designing, or redesigning, a pizza box.

The choice of testing a pizza box was not made by the instructors, it simply happened to 
be common to every group. Students were given only two stipulations: (1) requests for materials to use in experimentation were supplied to the instructors one week prior, and (2) company policy discouraged the use of actual pizza in the laboratory (due to safety considerations), thus pizzas had to be simulated by other means. Both of these stipulations proved to be excellent learning tools.

Each group had a conference with the instructors outside of class during the week prior to performing their experiments, in order to go over their (informal) experimental plan. They had all decided on a unique way of simulating a pizza (from Hot Pockets to bags of rice, or slices of bread) and had requested ample raw materials to do the tests they were interested in. In this sense it appeared that they had carefully planned their experiments. However, only one of five groups remembered to ask for simple experimental tools such as thermometers, stopwatches, measuring cups and a source of heat. In keeping with the general theme of the project, no information or resources were provided without a specific request, this was in effort to simulate a real work environment and the responsibility of an engineer. One cannot expect to walk into the laboratory and find a convenient supply of chemicals and equipment if one did not first order those materials. The instructors used the conference time to allow groups to request experimental tools in addition to the ones previously requested. Everybody had all the supplies they needed on the day of experiments.

The week following the in-class experiments, students brought in prototype solutions, and the instructors provided real pizza for testing. Additionally, several individuals from the department were asked to attend and judge the solutions. Each group gave a presentation (using PowerPoint) that included their unique problem definition, and they ways they had considered solving it. Each group also included data from their experiments (graphed in Excel) and discussed how it supported their final decisions.

The level of student maturity and achievement on this project astonished the instructors. With no instruction in the area of effective presentation planning, all groups presented wellorganized and professional presentations. Many of the written assignments also exhibited an impressive mastery of computer software and organization. These students rose to the challenge put to them and truly performed far beyond the instructors' expectations.

\section{Conclusions}

Student feedback at the end of the course was generally positive. Though a few students did not see value in the project, all admitted that the project had been enjoyable. Some students were frustrated that they were asked to be creative and then given limitations within which they had to work. Comments like "I still wonder if engineers in the real world use project plans" indicated a negative perspective on the project. However, from the instructor's perspective, the negative responses support the need of this type of project more than the positive ones. All of the activities that were disliked in this project will be encountered in future classes as well as engineering careers. 
There were several unexpected outcomes of this project. The survey given at the beginning and end of the semester to four sections of ENGR 1111 was largely inconclusive. Students in the project section were not significantly (confidence level of 0.95 ) more confident in their abilities than those in the other sections. Additionally, they showed less significant improvement (difference between beginning and ending responses) than the three other sections. On the surface these results are discouraging. However because the responses were based on student perception, it is possible that those students that actually learned about problem solving methods decreased the confidence level in their abilities over the semester. In other words, a student that came in thinking he knew what he was doing may have learned otherwise during the semester and changed his confidence score.

In proposing future studies, the method of assessment will need to include a more accurate measure of ability and rely less on student attitudes. Because this is the first semester that this has been implemented, it is impossible to tell whether students' creativity was enhanced and whether retention will be improved. However, the students were noticeably more active in class discussion as compared to previous classes. Some students are still corresponding with the instructor after the completion of the semester; this is a positive and unusual occurrence. Future studies will also be longitudinal in nature so effects of creativity on retention rate may be measured.

An interesting thing happened involving the personality typing the class completed. While personality types are often an excellent way to glean insight on personal preferences and strengths, when we actually applied this knowledge to the teams for the Pizza Project, the information became more meaningful to the students. Additionally, discovering the class personality type distribution gave insight to understanding the class' apparent enthusiasm for the course. Only two of twenty students were introverts, thus the highly interactive nature of the entire course was a positive learning environment for the class as a whole ${ }^{6}$. This personality distribution was very different from the other sections.

A major unexpected benefit of adding the project was the continuity it added to the course. All freshmen are required to complete certain library and Internet exercises, and also use Microsoft Word, Excel, and PowerPoint. Using the project as motivation for these activities made assignments easier for the instructor to develop, and made the tools realistically useful for the students. In retrospect, this project may have had a more positive influence on helping freshmen understand the role of an engineer, than it was an opportunity to express creativity. In either case, the improvement of classroom atmosphere and continuity of assignments that it brought were worth repeating. The instructors will use this technique again.

\section{References}

1. Jones IV, Jesse N., Livia Racz, and Chris Rogers, "Musical Instrument Engineering Program at Tufts University," Journal of Engineering Education, January 2001, pp. 101-103.

2. Higly, K. A., and C. M. Marianno, "Making Engineering Education Fun," Journal of Engineering Education, January 2001, pp. 105-107.

3. Goff, Kathy, Everyday Creativity, Little Ox Books, Stillwater, Oklahoma, 1998. 
4. Korgel, Brian A., "Nurturing Faculty-Student Dialogue, Depp Learning and Creativity through Journal Writing Exercises," Journal of Engineering Education, January 2002, pp. 143-145.

5. Fogler, H. Scott, and Steven E. LeBlanc, Strategies for Creative Problem Solving, Prentice Hall, Upper Saddle River, New Jersey, 1995.

6. Felder, R. M., G. N. Felder, and E. J. Dietz, "The Effects of Personality Type on Engineering Student Performance," Journal of Engineering Education, January 2002, pp. 3-17.

\section{Author Biographies}

CYNTHIA MANN will obtain a B.S. degree in Chemical Engineering from Oklahoma State University in May 2003. This is her first publication and she is looking forward to a career of many more. Cynthia's future educational plans include graduate studies in biomaterials and tissue engineering.

KAREN HIGH earned her B.S. from the University of Michigan in 1985 and her M.S. in 1988 and Ph.D. in 1991 from the Pennsylvania State University. Dr. High is an Associate Professor in the School of Chemical Engineering at Oklahoma State University where she has been since 1991. Her main interests are Environmental Process Design, Industrial Catalysis, and Creativity in Engineering Education. 